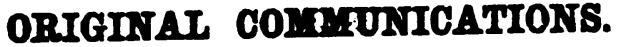

\section{CLINICAL LECTURES ON SURGERY NOW IN COURSE OF DELIVERY A'T QUEEN'S COLLEGE, BIRMINGHAM.}

By LANGSTON PARKER, Esq., Surgeon to the Queen's Hospital, and Professor of Anatomy in Quecu's College, Birmingham.

[Reported by James Jaffray, Esq., and corrected by the Author.] LECTURE III.

ON TUE MAYAGENENT OF STUMPS $\triangle$ FTER AMPUTATIONS, ETC.

Gentemexe, - Within a very short period, you have had an opportunity of seeing me remove, by amputation, four thighs, opportunity of the shoulder-joint. Perhaps, of all the operaand onc arm at the shoulder-joint. Perhaps, of the continuity of the extremities, that of the thigh is the most important. This arises from a great variety of circumstances; it arises, cspecially in strong subjects, and after accidents, from the great quantity of soft parts we have to cut through. Generally, the mortality following amputation of the thigh is greater than the mortality following amputation of the leg, of the forcarm, or of the upper arm. This, again, will be very casily understood. The mode generally adopted by me with regard to the remoral of the thigh and limbs gencrally, cxcept in the les, is either by lateral or upper and lower flaps. In the thigh, I always opcrate, except in peculiar circumstances, by lateral flaps, a flap made from in peculiar circumstances the inner side of the limb. In cutting flaps in this way, the knife should be passed into the limb on the inner side of the femur, then turned round the bone, and brought out on the opposite side. If this plan be not adopted, the flaps, when cut, are uneven in size; and this arises from tro circumstances, one dependent on the situa. tion of the femur, which is nearer the outer than the inner side of the limb; and the second, from the fact that the mass of muscle on the inner side of the bone is much greater relatirely than that on the outer side of it. Again, if you operate by an upper and lower flap, the knife should be introduced on a level with the lower border of the bone, passed down to it, turned orer, and brought out on the opposite side. If this bo not done, the flaps are again uneren in size, and from similar causes, viz., the situation of the femur ncarer to the anterior than the posterior aspect of the limb, and the existence of a greater mass of soft parts on its back part. The annexod outline shows a stump, the flaps of which have been cut in the manuer described.

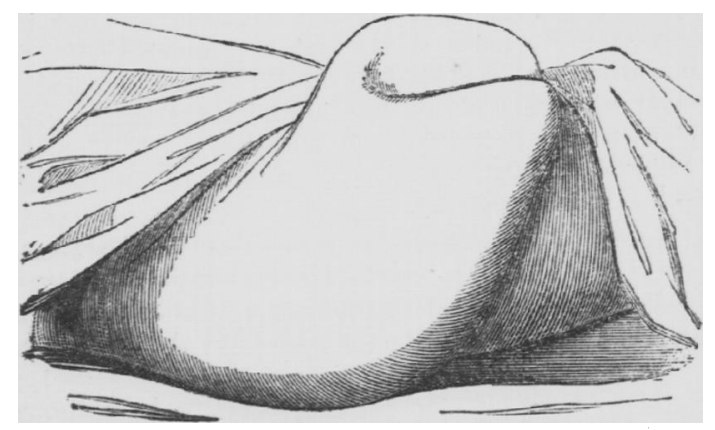

I have seen flaps cut where one has borne no sort of relation to the other, from neglect of the simple facts I have just stated.

We come now to consider the treatment of the stump after the operation-the chief point I have in view in this lecture, and one perhaps of as much importance as the right performance of the operation itself. After a limb has been remored, two kinds of hæmorrhage follow; these arise from the divided arteries and veins; the former is commanded more or less completely by the tourniquet, or by pressure on the main arterial trunk of the limb; the renous hæmorrhage is not thus commanded, and is left to exhaust itself; it generally arises from three sources, from the nuitself; it generally arises franches spread over the whole surface of the stump; from one or more large veins, which sometimes furnish a stream of blood for a considerable somètimes furnish a stream of and again from the medullary canal of the shaft of the divided bone.

These threc occasional sources of hæmorrhage, independent of subsequent arterial blecding, which we shall presently speak of, are reasons why a stump should not bo dressed or put up too soon. A continuous renous oozing, for long periods, frequently takes place from the medullary for long periods, fre after an amputation, especially in young subjects, and in amputations high up, near the upper cxtremities of long bones.*

I remember, a little time ago, removing the arm of a man who had met with one of those mill accidents so comman who had met with one of the arm was amputated very ligh up. It was not remored at the shoulder-joint: I tried to save that, and succeeded; but still the operation was performed very high up. In this case, a very curious circumformed very high up. illustrates what I have said. Hiemorstance arose, we medullary canal lasted for two dars in a contimuous stream, so much so that, if you had wished to close the stump, it would have been impossible, in consequence of such bleeding. I believe that the homorrhage in this case came from the cancellatcd structure of the head of the humerus.

In healthy persons, the canccllated structure of the heads of long bones, especially in young and healthy subjects, contains an immense quantity of blood, and it is from this source that the hamorrhage in such cases and in such situations proceeds. But there are other circumstances where the oozing from the medullary canal takes place, and these I have already explained.

Suppose now the limb remored and the arteries tied, and the surface sponged until no further hæmorrhage takes place. A roller should then be put round from the upper to the lower part of the limb. Supposing it is the thigh, the roller should commence at the upper part of the limb, and be brought down to the base of the flaps; the flaps should be then brought together, put gently in apposition, and confined by a strip of plaster placed across them : over that a cold water bandage or wet lint. Now, what is the object of putting on the roller? It is uncertain where you can conveniently close the parts so as to produce the best union ; if you leave the muscles unsupported and unconfined, retraction may take place, and the bone protrude; and it is to prevent this that the roller becomes useful. There is another advantage in the roller, not only does it prevent muscular retraction, but it supports the flaps. You ought not to close the stump (properly close it, I mean) immediately after the operation, for several reasons. The first is, that frequently after the patient has become warm in bed, had a cup of tca, and the dread of the operation is past, an arterial trunk which has not previously bled will, under the influence of warmth and reaction, begin to bleed, and sometimes to a considerable cxtent. If the stump has been put up, sou have the trouble and the annoyance of reopening it to find the arterial trunk, which puts the patient to great torture; for in eight or ten hours after the stump is closed, it becomes inflamed and very sensitive. The risk, then, of arterial hæmorrhage coming on-that is, from an artcry which has escaped your observation when the tourniquet has been removed, or from other causes, is one of the reasois why the stump should not be closed at once. This does not always happen; but it occurs very often. Again, bleeding of another kind is apt to take place. There will be, at times, renous oozing from the general surface of the stump, or from some large vein, or from the medullary cavity of the shafts of the bones. Here, then, are other reasons why the stump should not be too early closed. I have seen a stump so distended two days after an amputation-and it had not been put up very

* I hare chtered fully into the nature and causes of this bleeding in a scrarate publication, to which I refer the render: "On the Nature and 
early - that nearly a washhand-basin of venous coagula were taken from it. By too early closing you in reality prevent the process of healing. If you put on the bandage, rolling the limb downwards until you come to the flaps, the stump will sustain no harm eren if it is not completely closed for two or three days; and in the event of any of the circumstances to which $I$ have alluded, happening, it is easy either to secure an artery or to remore coagula. In addition to the circumstances which I have mentioned, there are others which must be taken into consideration in the attempt to heal quickly and well a stump after an amputation. A stump is a simple incised wound, and three pathological stages take place after all incised wounds, which do not heal by what is called the first intention. First we have the effusion or flow of blood, whether arterial, or venous, or both, consequent upon the dividing the soft parts. When this has ceased, or has been controlled or arrested, the surface of the incision becomes corered with a layer of fibrin, and it is at this period that all incised wounds should be closed; if suffered to remain open after this, or if the attempt to unite them has failed; the wound secretes pus, and must then heal by a slower process-that of granulation. It is during the second period to which 1 hare alluded, when the flow of blood has ceased, and the effusion of fibrin has commenced, that the flaps of a stump should be brought methodically together and well supported, in order to insure an early and sound union.

To digress for a moment, it is generally supposed that the patient is better if he bleeds little; but, for my own part, I think a moderate loss of blood is rather an advantage to the patient. Wefind that if called on to perform an operation after an accident, upon a patient in full health and with a system full of blood, the bleeding goes on to a longer period, and the patient loses more blood than would a patient who has been worn out by a long continuance of disease. There is generally more venous oozing in such cases, and a greater risk of secondary arterial hremorrhage than in patients who have becn operated on for chronic diseases, and whose constitutions are more or less anæmic or debilitated. In such a class of cases, the stump heals frequently better than it would do in the first; and this arises simply from the cir cumstance that there is less renous oozing, which often interferes with the adhesion or union of the soft parts. Then coines a third period: the secretion of pus. Thus you have first, the venous oozing; second, the effusion of lymph-which is the period at which an incised wound ought to be closed; and third, the secretion of pus. If you close the wound at the second period, you are almost certain to get union by what is termed the first intention. If you wait a still longer period, a degree of intlammation and irritation takes place, there is an cffusion of pus; and as in the case of the hrmorrhage I have spoken of, the healing of the wound is retarded. The proper period to select for the closing of the wound, then, is that between the time when the flow of blood has ceased, and the secretion of pus may be expected. Such are the principles which are to guide you in the treatment of stumps. They are principles which exist in nature, and are founded on actual pathological laws which invariably take place, and a knowledge of these laws will always be serviceable to you, in whatever circumstances you may be placed.

Birmingham, April 1855.

THE MODERN TREATMENT OF FRACTURES.

By BENJAMIIN HCNT, Surgeon to the General Dispensary, Birmingham; late liesident Surgeon to the Queen's Hospital.

[The Substance of a Paper read brfore the Birmingham and Miclland Counties Rranch, Fichruary 8!h, 185.5.]

ThE modern treatment of fractures is a term applicd in this paper to the treatment of fractures of the bones of the limbs by closely fitting cases or moulds-a process which has received much attention during the last jear or two in this country as the starch apparatus, but which was originally this country as the starch ap $\mathrm{M}$. Seutin. I have designated this plan of treating fractures as the modern, because I do not so much wish to adrocate the practice in detail as in the abstract. Although starch has been employed as the adhesive and strengthening material in the cases I am about to describe, still, however, other substances have been used successfully, such as dextrine, and plaster of Paris, which, while they do not in the least alter the principles of the while they do not in the least alterch apparatus" inapprotreatment, yet make the name "starch ap the modern treatpriate. Another reason for calling this the mention is made ment is, that it is now in use ; and, though mention is made yet certainly it was not described in a systematic manner yet certainly it was M. Seutin's work on this subject appeared.

The advantages of treating fractures occurring to the bones of the limbs by means of closely fitting cases, which exert an equable pressure when applied, have been lucidly set forth in a work written by Mr. Gamgee; and to this book I may refer you for a very careful description of the manner of applyiug the starch apparatus: but, as my own independent experience has led me to adopt a few slight changes, I will endearour to give an outline of the method I have found most efficient.

The matcrials requisite for treating every kind of fracture of the extremities, whether simple, compound, or comminuted, in which an attempt is to be made to sare the limb, cousist of starch, millboard, lint, and bandages, and a few picces of wood of requisite length to serve as temporary outside supports until the apparatus has, by drying, become sufficiently strong to take the place of the broken bone.

The starch, which should not be made ready until required for immediate use, is prepared as by laundresses, but of a consistence twice as thick as used by them. The millboard is the same as book-covers are made of, stout and porous. The bandages may be of the commonest calico, five or six yards long, and the width of the tips of three fingers.

The limb to be operated on having been placed in such position as the nature and site of the injury seem to require, and the fragments having becn brought into apposition, it will be the intention of the opcrator to include the whole of the limb below the injury, and, in most instances, to continue the application of the apparatus so as to fix the joint above. Thus, for fracture of the tibia and fibula, the apparatus should reach from the clefts of the toes to half way up the thigh, that the lnce-joint may be included, and so rendered immoveable. Pads of lint are so placed as to protect the superficial bones from pressure; and the limb is bandaged firmly and evenly through the extent the apparatus is to be applied. This surface of bandage is thickly smeared over with starch ; and next, the millboard splints, prepared in the following manner, are adjusted. Upon a sheet of millboard make an outline of the shape of the limb, accordine to the position the splints are to oceupy; and, having cut them out in this manner, as many as nay be required, let them be steeped in boiling hot water until thoroughly saturated; they are then to be pressed between the folds of a dry cloth, to free them from the water which adheres to the surface: and now the edges may be scraped thin, roughly berelled as it were, so that, when dry, the splints may not have a defined square edge, which night hurt the patient. The splints are now placed in the desired situation, and moulded with the hands of the surgeon so as to adapt them closely to cvery incquality of the surface on which they are placed. $A$ thick layer of starch is next laid on, and over all a bandage. The apparatus is now complete, and, when dry, forms a closely fitting case, and of ample strength. Until the case has become dry, which generally happens in thirty-six or forty-eight hours, it may be desirable to fix on some wooden splints, to prevent the limb from becoming curved through accident or restlessness on the part of the patient. It might appear that, in some instances, wooden splints would be required to kcep up extension, as well as to support the limb, until the apparatus 